\title{
BMJ Open Effect of maternal origin on the association between maternal height and risk of preterm birth in Belgium: a retrospective observational cohort study
}

Virginie Van Leeuw, ${ }^{1}$ Charlotte Leroy, ${ }^{1}$ Yvon Englert, ${ }^{1,2}$ Wei-Hong Zhang ${ }^{1,2}$

To cite: Van Leeuw $V$, Leroy C, Englert Y, et al. Effect of maternal origin on the association between maternal height and risk of preterm birth in Belgium: a retrospective observational cohort study. BMJ Open 2018;8:e020449. doi:10.1136/ bmjopen-2017-020449

- Prepublication history for this paper is available online. To view these files, please visit the journal online (http://dx.doi org/10.1136/bmjopen-2017020449).

Received 3 November 2017 Revised 16 January 2018 Accepted 15 February 2018
Check for updates

${ }^{1}$ Perinatal Epidemiology Center (CEpiP), Non-profit Organisation, Bruxelles, Belgium

${ }^{2}$ Research Laboratory for Human Reproduction, Faculty of Medicine, Université Libre de Bruxelles (ULB), Bruxelles, Belgium

Correspondence to Professor Wei-Hong Zhang; wzhang@ulb.ac.be

\section{ABSTRACT}

Objectives To investigate the effect of maternal origin on the association between maternal height and the risk of preterm birth (PTB).

Design Retrospective observational cohort study.

Setting Two of the three Belgian regions, including Brussels-Capital and Walloon regions.

Participants A total of 245204 women spontaneously delivered live singletons between 2009 and 2013.

Maternal nationality at the time of birth included Belgium, Congo, French, Italy, Morocco, Poland, Romania and Turkey. Outcomes measures The outcome variable was spontaneous PTB, defined as childbirth occurring at less than 37 weeks' gestation.

Results Average height, demographic characteristics and the spontaneous PTB rate differed according to maternal origin, defined as maternal nationality at birth. The pattern of association between maternal height and the risk of PTB was not uniform by maternal nationality at birth. The low maternal height category was associated with a statistically significant increased risk of spontaneous PTB for Belgian (adjusted OR (aOR) 1.23, 95\% Cl 1.16 to 1.32), Italian (aOR 1.48, 95\% $\mathrm{Cl} 1.12$ to 1.96) and Polish (aOR $1.76,95 \% \mathrm{Cl} 1.11$ to 2.78 ), respectively. However, this association was not observed for the women from Congo, France, Morocco, Romania and Turkey.

Conclusions The association between height and the risk of PTB was modified by maternal nationality, even for mothers from the same region of the world. For example, there was a significant inverse association for the Belgians and Italians but not for French women. Our data suggest that PTB risk assessment should take into account the specific height of maternal origin.

\section{INTRODUCTION}

Preterm birth (PTB), defined as childbirth occurring at less than 37 completed weeks, remains the leading cause of perinatal morbidity and mortality. ${ }^{12}$ An estimated 14.9 million preterm infants were born in 2010 , accounting for $11.1 \%$ of all live births worldwide, ranging from approximately $5 \%$ in European countries to $18 \%$ in African countries. $^{2}$ The main causal factors linked to PTB include medical conditions in the

\section{Strengths and limitations of this study}

- This is a retrospective observational cohort study, including a large number of migrant mothers in Belgium, which allowed us to construct eight nationality groups comprising a sufficient number of individuals to perform stratification by maternal nationality at birth.

- This is the first study to analyse the association between maternal height and preterm birth by examining the homogeny of maternal origin.

- No detailed information regarding obstetrical history, maternal smoking, nutritional status or biological and genetic markers was available.

mother or the fetus, genetic influences, environmental exposure, infertility treatments, behavioural and socioeconomic factors, and iatrogenic PTB. ${ }^{3}$

The association between maternal height and the risk of PTB has been investigated..$^{4-10}$ Some studies showed an inverse association between maternal height and PTB, ${ }^{4}{ }^{10}$ but some studies did not find any significant association. ${ }^{5-9}$ A recent study demonstrated that the association between height and the risk of PTB varied across various ethnic groups in USA. $^{11}$

Belgium has long been a country of immigrants and has become a country with one of the largest foreign-born populations; $44.9 \%$ of deliveries in Belgium in 2013 were to foreigners living in the country (ie, women not of Belgian nationality when giving birth). ${ }^{12}$ These foreign women were mainly economic migrants (Italian) in the early 20th century or people affected by family reunification (Morocco). They also include civil servants from European institutions or international institutions in high-income countries, as well as asylum seekers and undocumented workers from low-income and middle-income countries. 
The Centre for Perinatal Epidemiology (CEpiP) in Belgium collects mandatory perinatal official data from Wallonia and Brussels and covers all the deliveries in the two regions regardless of citizenship. Information regarding maternal nationality both at birth and at delivery is available for each woman in CEpiP's database.

The aim of this study is to investigate the association between maternal height and the risk of PTB stratified by maternal nationality at birth. We use the nationality of each mother at birth without any categorisation, which allows us to construct highly homogeneous groups within the study population.

\section{METHODS}

\section{Study design}

This was a retrospective cohort study, using the population-based data linking birth registry and hospital medical data.

\section{Setting}

The setting for the study was two of the three regions in Belgium, including Brussels-Capital and Walloon regions. Brussels is located in the centre of the country, and Wallonia is the Southern part of Belgium. The total annual number of births in the two regions is approximately 62000 and covers 47 maternity units, and the majority of deliveries $(99.6 \%)$ take place in maternity units. ${ }^{12}$

\section{Data sources}

The study population consisted of all single live births from 2009 to 2013 in the database of the CEpiP in Belgium. The database linked the routing data of birth registry and hospital medical data. The birth registry legally includes certificates of all live births or stillbirths from $500 \mathrm{~g}$ or 22 weeks' gestation regardless of maternal citizenship, including asylum seekers, undocumented persons, planned and unplanned home births. The socioeconomic data were completed by the civil registration service or by parents when declaring the birth/death within 15 days of delivery. The hospital medical data are collected and completed by care providers in each maternity unit. The details of this linkage, data management and verification have been described previously. ${ }^{13}$ Briefly, CEpiP-linked routing data contained information regarding maternal demographics, including maternal origin, maternal risk factors, medically assisted procedures, delivery method and perinatal outcomes. Linked data are available for 299840 live births and 2132 stillbirths during 2009-2013.

Two variables related to the maternal origin were available in CEpiP's database: one is the nationality of the mother at her birth (named 'maternal nationality at birth'), and the other is her nationality at delivery (named 'maternal nationality at delivery').

\section{Participants}

Participants included single live births from 2009 to 2013 in CEpiP's-linked database who met the inclusion criteria.

The inclusion criteria were as follows: singleton live births, spontaneous delivery, born at 22-42 weeks of gestation and women who had nationality at birth from the eight most represented nationalities in the database, including Belgium, Congo, France, Italy, Morocco, Poland, Romania and Turkey.

The reason for including only the eight most represented nationalities is based on the estimation of the sample size in logistic regression analysis to achieve predictive stability. ${ }^{14}$ Assuming an average PTB rate of $5 \%$ in each model of the eight nationalities, and eight predictor variables contained in the model, at least 10 events per variable, a total of 80 events (PTB) or at least 1600 subjects $(80 / 5 \%)$ were required in each model, with $80 \%$ power and a two-sided significance level of $5 \%$. Among the eight nationalities meeting the sample size estimation and included in the analysis, the largest categories were Belgian ( $\mathrm{n}=69705)$, Moroccan $(\mathrm{n}=14046)$, French $(\mathrm{n}=5020)$, Italian $(\mathrm{n}=3922)$, Turkish $(\mathrm{n}=3259)$, Congolese $(n=2924)$, Romanians $(n=2904)$ and Polish $(\mathrm{n}=1924)$.

Exclusion criteria were as follows: induction of labour or elective caesarean (defined as a section planned before the onset of labour), gestational weeks at delivery $<22$ or $>42$, birth weight $<500 \mathrm{~g}$, maternal age $<18$ years, unknown level of education and missing body mass index (BMI).

\section{Variables}

The prepregnancy weight and maternal height were registered at the first prenatal consultation at $<12$ weeks or based on self-reports if the first consultation was held $>12$ weeks. In this paper, the maternal nationality is defined as the maternal nationality at birth.

To obtain an overview of the distribution of maternal height among maternal nationalities, we calculated the 25th, 50th and 75th percentile values of maternal height based on the entire obstetric population (all deliveries). Furthermore, in order to compare among the included population, maternal height was classified into three categories based on height distribution, namely, $<25$ th (short), 25th-75th (middle) and $>75$ th (tall), specific for each maternal nationality, with the middle category serving as reference.

Potential confounding factors for PTB based on previous study and availability on CEpiP's database included the following: maternal age (<25, 25-34 and $\geq 35$ years), maternal education based on the highest level achieved (secondary or less, postsecondary or higher), employment status (yes, no), parity (primipara, multipara), maternal BMI $\left(<18.5 \mathrm{~kg} / \mathrm{m}^{2}, 18.5-24.9 \mathrm{~kg} / \mathrm{m}^{2}, \geq 25.0 \mathrm{~kg} /\right.$ $\mathrm{m}^{2}$ ), gestational or permanent hypertension (yes, no), gestational or permanent diabetes (yes, no), medically assisted conception (yes, no). 


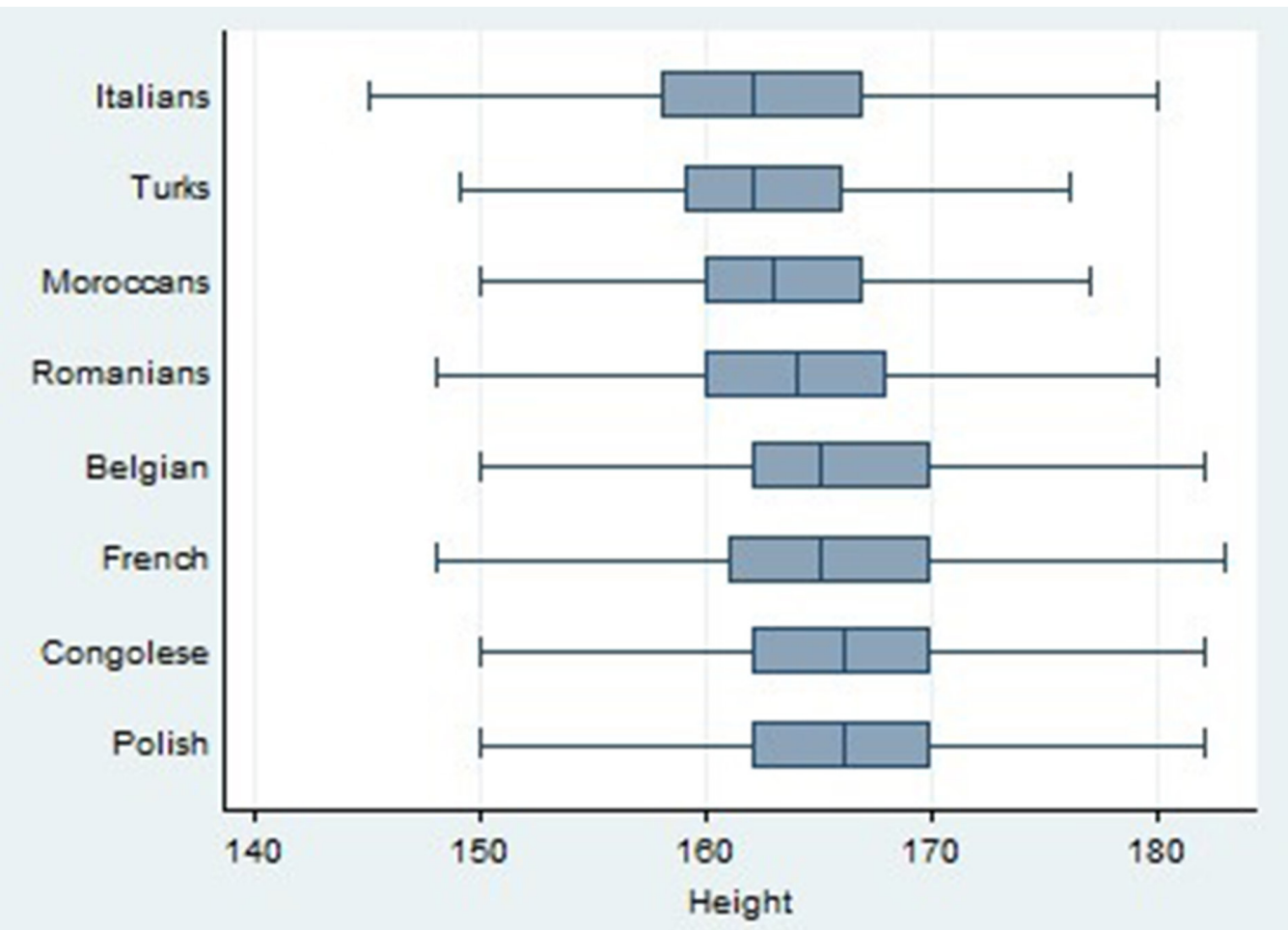

Figure 1 Box plot of maternal height for the overall obstetric population in eight groups according to maternal nationality at birth. The bottom (left) and top (right) of the box represent 25th and 75th percentiles, the band in the middle represents the median (50th percentile). The lower whisker represents the minimum value of the data while the upper whisker represents the maximum value of the data (analysis of variance, $p<0.001$ ).

\section{Main outcome and measurement}

The outcome variable was spontaneous PTB, defined as childbirth occurring at less than 37 completed weeks. The spontaneous birth includes all deliveries after a spontaneous labour.

\section{Statistical methods}

Baseline characteristics of the study population were summarised with counts (percentages) for all categorical variables. Continuous variables were tested with one-way analysis of variance (ANOVA). Categorical variables were compared with the $\mathrm{X}^{2}$ test. Occurrence of spontaneous PTB at $<37$ weeks and its $95 \%$ CI was estimated for each maternal nationality. To determine the relationships between maternal height and risk of spontaneous PTB, crude OR and 95\% CI were calculated across the maternal nationalities. Logistic regression models were used for controlling eight confounding variables such as maternal age, maternal education, employment status, parity, maternal BMI, hypertension, diabetes and medically assisted conception. Models were stratified by maternal nationality.

All tests were two tailed and used significance level set at 0.05. All analyses were performed using Stata V.14.0 software.

\section{Ethics approval}

Individual information was not available.

\section{RESULTS}

A total of 245204 women delivered in two regions from 2009 to 2013 and belong to eight groups according to maternal nationality. Missing data on maternal height were $10.1 \%$ for all deliveries $(\mathrm{n}=24763)$. The 25 th, 50 th and 75th percentile values of maternal height of entire obstetric population (all deliveries) who had available data on maternal height were calculated $(n=220441)$ (figure 1). Calculation based on the overall obstetric population allowed us to obtain an overview of the distribution of maternal height according to maternal origin and to avoid selection bias by excluding non-spontaneous labour for obstetric indications. The average (SD) height from lowest to the highest was $162 \mathrm{~cm}$ (5.7) for Turks $(\mathrm{n}=6601), 162 \mathrm{~cm}(6.3)$ for Italians $(\mathrm{n}=9079), 163 \mathrm{~cm}(5.9)$ for Moroccans ( $\mathrm{n}=28$ 021), $163 \mathrm{~cm}$ (6.5) for Romanians $(\mathrm{n}=4195), 165 \mathrm{~cm}$ (6.3) for French $(\mathrm{n}=9879), 165 \mathrm{~cm}$ (6.4) for Belgians $(\mathrm{n}=152414), 166 \mathrm{~cm}$ (5.9) for Polish $(\mathrm{n}=3732)$ and $166 \mathrm{~cm} \mathrm{(6.5)}$ for Congolese $(\mathrm{n}=6520)$. Through one-way ANOVA, we found that the difference of mean height between the eight groups was statistically significant $(\mathrm{p}<0.001)$.

For the eight groups of maternal nationality most represented in CEpiP's database, there were 220441 pregnancies with height information; 215767 singleton live births were identified and linked, and 89580 subjects were excluded due to induction of labour or elective caesarean (41.5\% of singleton live births). Births were also excluded 
if the gestational weeks at delivery were $<22$ or $>42$ or unknown $(\mathrm{n}=52)$, birth weight $<500 \mathrm{~g}(\mathrm{n}=12)$, maternal age $<18$ years $(n=1005)$, unknown level of education $(n=19$ $002)$ and missing BMI $(n=3240)$. Therefore, a total of 102 876 births across eight nationalities were included in the following univariate and logistic regression analyses.

The characteristics of mothers differed according to maternal nationality for all variables in table $1(\mathrm{p}<0.001)$. Concerning the socioeconomic characteristics, mothers from Belgium, French and Italy were more educated and more employed than women from Poland, Romania, Congo, Morocco and Turkey. Regarding medical characteristics, mothers from three non-European countries (Congo, Morocco and Turkey) were more frequently multiparous and more overweight. In contrast, these women had less usage of medically assisted treatment. The highest proportion of diabetic women was found in Moroccan women $(8.3 \%)$, and the lowest proportion of diabetic women was found in Romanian women $(4.1 \%)$. For the frequency of hypertension, the highest was observed for women from Congo $(6.4 \%)$ and lowest for women from Morocco (1.7\%) and Romania (1.8\%).

Figure 2 shows that the PTB rate varied among the various maternal nationalities. Rates were highest for women from Italy $(7.7 \%)$ and Belgium $(7.6 \%)$ and lowest for Moroccan women $(4.5 \%)$. There were similar trends between PTB rate and the maternal height categories: the lower the maternal height, the higher the PTB rate, except for Congolese, Romanian and Polish women, where the PTB rate in the tall group were slightly higher than that of the middle group (table 2).

The effects of maternal nationality at birth on the association between height and the risk of PTB are displayed in table 3 . Compared with the middle height category, the low height category was associated with a statistically significant increased risk of spontaneous PTB, with an adjusted OR (aOR) of 1.23 (95\% CI 1.16 to 1.32) for Belgians, 1.48 (95\% CI 1.12 to 1.96) for Italians and 1.76 (95\% CI 1.11 to 2.78) for Polish. This relationship was not statistically significant for the remaining five nationality groups, although a similar inverse association was observed with or without adjustment for maternal age, education level, employment status, parity, maternal BMI, hypertension, diabetes and medically assisted conception.

The direction and strength of the associations between higher height categories and the risk of PTB was less pronounced (table 3 ). After adjustment, the higher height category was significantly associated with a decreased risk of spontaneous PTB only for Belgians, with an aOR of 0.82 (95\% CI 0.76 to 0.89$)$.

\section{DISCUSSION}

\section{Main findings}

This study examined the association between maternal height and the risk of spontaneous PTB according to maternal origin, defined as the maternal nationality at birth without any categorisation of nationality according to region. Various maternal origins had various height distributions and various spontaneous PTB rates. Maternal origin influenced the association between height and the risk of PTB. These differences also existed for the women from same world regions or same income group. Belgian, Italian and French women have been grouped into same subgroup in previous studies of the effect of maternal origin on birth outcome.

Maternal short stature as a risk factor for PTB has been investigated previously with mixed results. A significant association has been found in a large study reported by Smith $e t a l{ }^{5}$ in a study that examined teenage pregnan$\operatorname{cies}^{7}$ and in a study done by Kramer et al. Some studies did not demonstrate that maternal height predicted the risk of PTB, such as in Germany, ${ }^{15}$ Great Britain, ${ }^{8}$ Sudan $^{4}$ and among a homogeneous Chinese population. ${ }^{16} \mathrm{~A}$ significant association was found in a univariable model or unadjusted data but not for multivariable model or adjusted data. ${ }^{6910}$ These mixed results could be partly due to varying definitions of short stature or height cut-offs, variation in quality of studies, heterogeneous populations and small sample sizes in the subgroups. ${ }^{11} 17$

\section{Effect of maternal origin on the association}

Our findings are consistent with those of a recent study conducted in California, which showed that patterns of association between height and risk of spontaneous PTB varied according to the maternal ethnicity. ${ }^{11}$ In the present study, an inverse significant association between height and risk of PTB was found for Belgians, Italians and Polish. However, this association was not observed for women from Congo, France, Morocco, Romania or Turkey. Our findings are in line with studies supporting maternal origin as a modifier in a similar manner. For example, a study from Canada reported that the association between area characteristics and birth outcomes was modified by maternal birthplace: area poverty was associated with PTB among Canadian-born women but not among foreign-born mothers. ${ }^{18}$ Another study from the USA reported that cumulative exposure to income inequality was associated with PTB for Hispanic mothers but not for black or white mothers. ${ }^{19}$ The causes of birth outcome disparities by maternal origin are complex and unclear. During recent decades, disparities in adverse birth outcomes have been documented across subgroups of maternal origin, including ethnicity, maternal place of birth, maternal nationality at birth and migrant status.

Some studies reported worse birth outcomes for foreign-born women compared with native women, with more obstetrical interventions, perinatal mortality, ${ }^{20}$ low birth weight, ${ }^{21} \mathrm{PTB}^{22}$ and increased caesarean section. ${ }^{23}$ Some studies showed mixed results. ${ }^{24}{ }^{25}$ These inconsistent results could be partly explained by grouping women with different origins, cultures and maternal characteristics into the same subgroups according to ethnicity classification, geographical regions or income groups. ${ }^{24}$ 


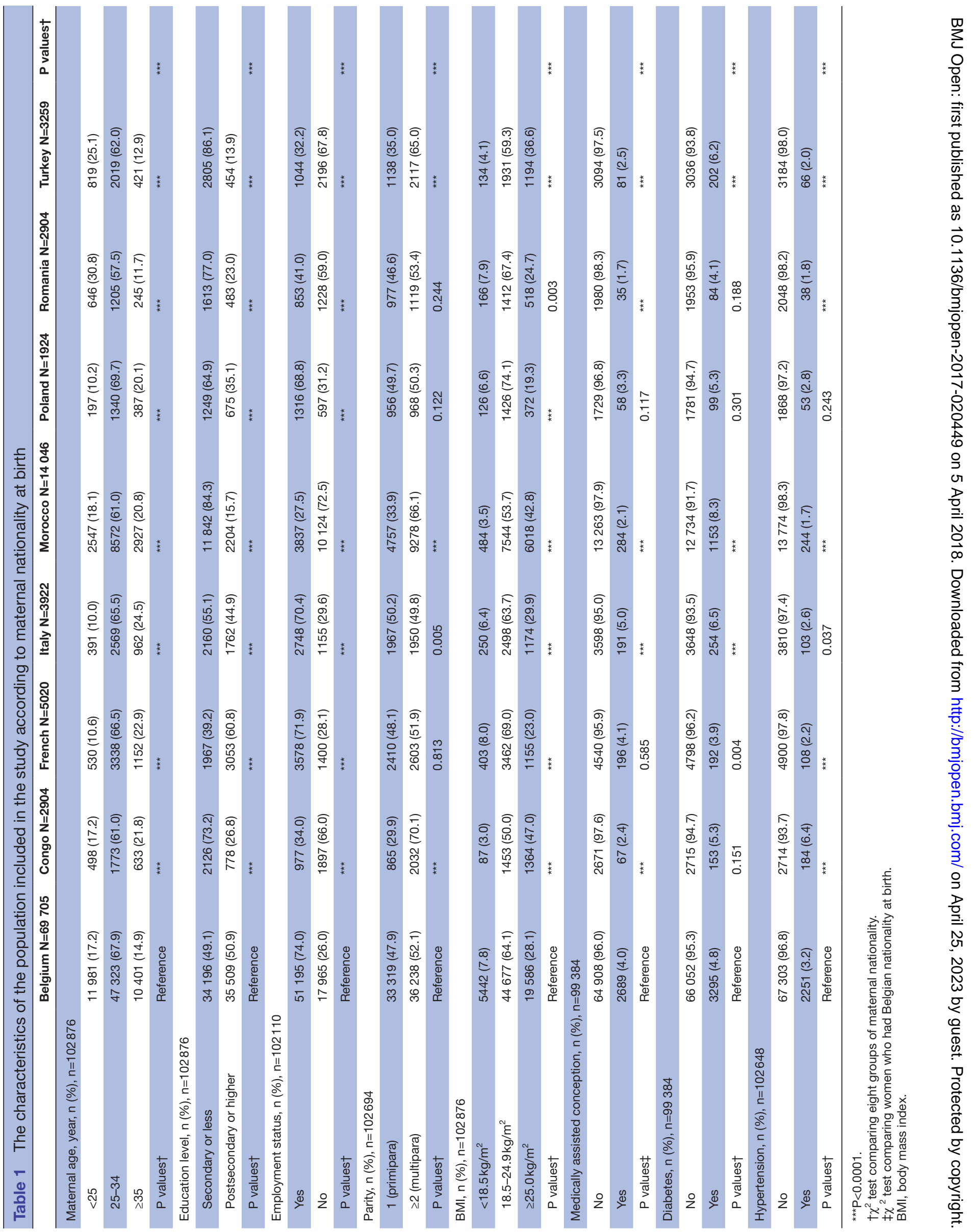




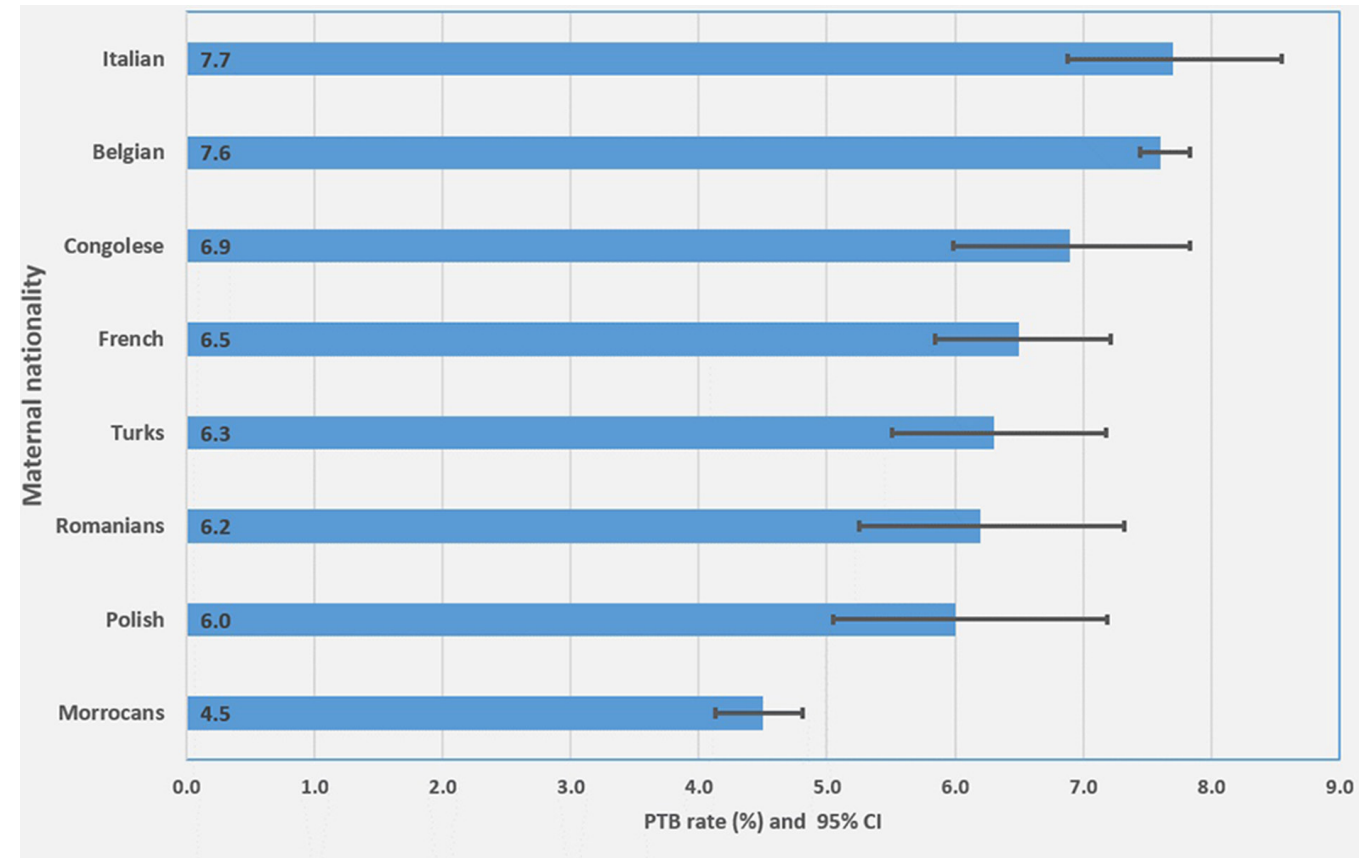

Figure 2 Preterm birth (PTB) rate and 95\% Cl for eight selected groups of maternal nationality at birth.

For many maternal characteristics, the present data showed a significantly different pattern among the selected eight groups of maternal nationality at birth. These variations persisted among the Belgian, French and Italian women who are categorised into the same subgroup of high income according to the definition of the World Bank Atlas Method (http://data.worldbank. org/), which is often used in Europe for classification of immigrant's country in the previous studies. ${ }^{25}$ It may be more appropriate to analyse the association between the maternal height and the risk of PTB separately according to their own nationality group, in order to avoid the effect of heterogeneity within the subgroup.

We show herein that the variation in the rate of PTB differed according to maternal nationality, the lowest rate being for Moroccan women. This has also been reported in a previous study in the Netherlands that demonstrated a higher risk of PTB for Surinamese and Ghanaian women compared with Dutch women but a lower risk for Turkish and Moroccan women. ${ }^{26}$ A study in the USA reported that Arab-Americans had a lower risk for PTB than white Americans. ${ }^{27}$

\section{Mechanisms between maternal stature, risk of PTB and role of maternal origin}

A few possible mechanisms have been proposed to explain the relationship between maternal stature and risk of PTB. Genetic, transgenerational, early life and environmental factors may play a role in this relationship. Pelvic dimensions and shapes vary as well among ethnic groups. ${ }^{28} \mathrm{~A}$ small pelvis was more prevalent in women with short stature. ${ }^{29}$ If maternal short stature leads to shortened gestation by increasing the risk of idiopathic preterm labour, then short women had more risk of PTB. ${ }^{30}$ Short maternal stature was associated with lower uterine volume and blood flow, increasing the risk for

Table 2 Spontaneous preterm birth (PTB) (<37 weeks) rate by maternal height categories in eight selected groups of maternal nationality at birth

\begin{tabular}{|c|c|c|c|c|c|c|}
\hline \multirow[b]{2}{*}{ Maternal nationality } & \multicolumn{3}{|c|}{ Overall PTB } & \multicolumn{3}{|c|}{ PTB by height categories } \\
\hline & Rank & $\mathbf{n}$ & $\%$ & Short \% & Middle \% & Tall \% \\
\hline Italian ( $n=3922)$ & 1 & 301 & 7.7 & 10.3 & 7.2 & 5.9 \\
\hline Belgian ( $n=69$ 705) & 2 & 5321 & 7.6 & 9.4 & 7.4 & 6.0 \\
\hline Congolese $(n=2904)$ & 3 & 199 & 6.9 & 7.2 & 6.3 & 7.7 \\
\hline French $(n=5020)$ & 4 & 326 & 6.5 & 7.3 & 6.8 & 4.6 \\
\hline Turks $(n=3259)$ & 5 & 205 & 6.3 & 7.8 & 6.2 & 4.9 \\
\hline Romanians ( $(n=2904)$ & 6 & 130 & 6.2 & 7.0 & 5.8 & 5.9 \\
\hline Polish ( $n=1924)$ & 7 & 116 & 6.0 & 8.6 & 4.9 & 5.7 \\
\hline Moroccans ( $\mathrm{n}=14$ 040) & 8 & 626 & 4.5 & 4.9 & 4.3 & 4.1 \\
\hline
\end{tabular}


Table 3 Maternal height and risk for preterm birth $<37$ weeks according to the maternal nationality at birth

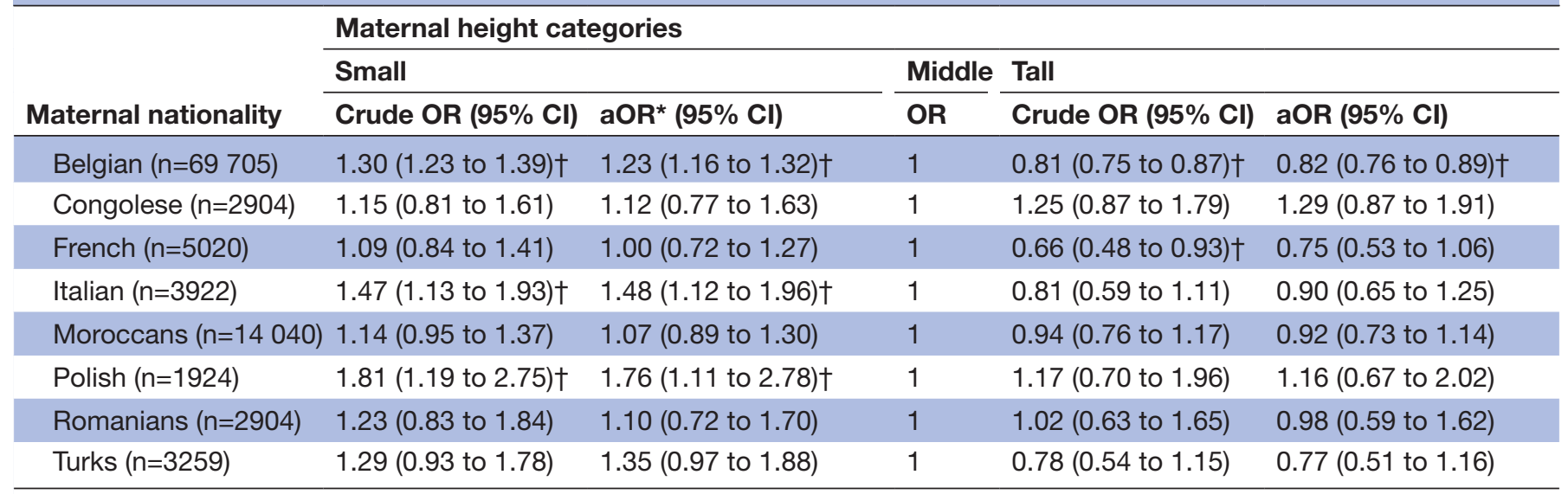

*Adjusted for: maternal age, education level, employment status, parity, maternal BMI, hypertension, diabetes and medically assisted conception.

† P-value $<0.001$

aOR, adjusted OR; BMI, body mass index.

fetal grow restriction, cephalopelvic disproportion and caesarean section. ${ }^{29}$ The effect of ethnicity on gestational length was also reported in a study in the UK. ${ }^{31}$ Maternal short stature may be associated with a lack of nutrients. Undernourished girls often grow up to become women of below-average height and often give birth to smaller infants. ${ }^{30}$ Shorter women having chronic malnutrition may be more likely to have infection during pregnancy, resulting a high risk of PTB. ${ }^{32}$ Placental epigenetic modification contributes to intrauterine growth and to adulthood height determination. ${ }^{33}$

\section{Limitations and strengths}

Several limitations of the present study should be highlighted. First, certain maternal and fetal risk factors for PTB were not accounted for, including smoking, prior PTB, nutritional status, infection, acculturation, stress/ depression, family support, uterine contractions, cervical length and biological/genetic markers. All these factors may confound or modify the relationship between height and PTB. Second, our findings should be interpreted with caution because of a high rate of missing or incomplete information regarding height (10\%), educational level (18\%) and BMI (3\%), although the proportion of these missing data did not vary across the eight groups of maternal nationality. Third, the analysis was limited by the reporting and coding in the database which was linked from birth certificates and hospital discharge data. In particular, weight was self-reported if the first consultation was held $>12$ weeks. In addition, diabetes and hypertension were documented in different forms, either pre-existing or recognised during pregnancy, regardless of the diagnostic criteria used. Several techniques and definitions may have been used across the country, and we cannot exclude that this could affect our results.

The strength of our study is that it is population based, with a low rate of missing data and a large set of covariates. Another strength is the availability of a large number of migrant mothers in Belgium, which has allowed to construct eight nationality groups including enough individuals to perform stratification by maternal nationality at birth. This allowed us to overcome the heterogeneity of misclassification bias of subgroups due to a small number of subjects in each group. To our knowledge, this is the first study to analyse the association between maternal height and РTB according to maternal nationality at birth.

\section{CONCLUSION}

The association between height and the risk of PTB is modified by maternal nationality, even for mothers from the same region of the world. For example, there was a significant inverse association for Belgian and Italian, but not for French women. Our results suggest that PTB risk assessment should take into account both height and maternal origin.

Acknowledgements We thank the Brussels Health Observatory and the Health Department of the French Community of Belgium for their help in gathering the databases.

Contributors VVL participated in gathering and correcting the data and contributed to the design of the study and analysing data. CL participated in gathering and correcting the data and in revising the manuscript. YE participated in the design of the study and in revising the manuscript. W-HZ participated in the design of the study and in drafting the manuscript. The final manuscript has been read and approved by all the authors.

Funding The study was supported by the grant from the Wallonia and Brussels Health Observatory.

Competing interests None declared.

Patient consent Not required.

Ethics approval No ethical approval was required as this study extracted anonymous data from the CEpiP database.

Provenance and peer review Not commissioned; externally peer reviewed.

Data sharing statement The dataset supporting the conclusions of this article are available on request at CepiP perinatalite@cepip.be

Open Access This is an Open Access article distributed in accordance with the Creative Commons Attribution Non Commercial (CC BY-NC 4.0) license, which 
permits others to distribute, remix, adapt, build upon this work non-commercially, and license their derivative works on different terms, provided the original work is properly cited and the use is non-commercial. See: http://creativecommons.org/ licenses/by-nc/4.0/

(C) Article author(s) (or their employer(s) unless otherwise stated in the text of the article) 2018. All rights reserved. No commercial use is permitted unless otherwise expressly granted.

\section{REFERENCES}

1. Beck S, Wojdyla D, Say L, et al. The worldwide incidence of preterm birth: a systematic review of maternal mortality and morbidity. Bull World Health Organ 2010;88:31-8.

2. Blencowe $\mathrm{H}$, Cousens $\mathrm{S}$, Oestergaard $\mathrm{MZ}$, et al. National, regional, and worldwide estimates of preterm birth rates in the year 2010 with time trends since 1990 for selected countries: a systematic analysis and implications. Lancet 2012;379:2162-72.

3. Goldenberg RL, Culhane JF, lams JD, et al. Epidemiology and causes of preterm birth. Lancet 2008;371:75-84.

4. Elshibly EM, Schmalisch G. The effect of maternal anthropometric characteristics and social factors on gestational age and birth weight in Sudanese newborn infants. BMC Public Health 2008;8:244.

5. Smith GC, Shah I, White IR, et al. Maternal and biochemical predictors of spontaneous preterm birth among nulliparous women: a systematic analysis in relation to the degree of prematurity. Int $J$ Epidemiol 2006;35:1169-77.

6. Meis PJ, Michielutte R, Peters TJ, et al. Factors associated with preterm birth in Cardiff, Wales. II. Indicated and spontaneous preterm birth. Am J Obstet Gynecol 1995;173:597-602.

7. Lao TT, Ho LF. Relationship between preterm delivery and maternal height in teenage pregnancies. Hum Reprod 2000;15:463-8.

8. Honest $\mathrm{H}$, Bachmann LM, Ngai C, et al. The accuracy of maternal anthropometry measurements as predictor for spontaneous preterm birth-a systematic review. Eur J Obstet Gynecol Reprod Biol 2005;119:11-20.

9. Savitz DA, Dole N, Herring AH, et al. Should spontaneous and medically indicated preterm births be separated for studying aetiology? Paediatr Perinat Epidemiol 2005;19:97-105.

10. Han Z, Lutsiv O, Mulla S, et al. Maternal height and the risk of preterm birth and low birth weight: a systematic review and metaanalyses. J Obstet Gynaecol Can 2012;34:721-46.

11. Shachar BZ, Mayo JA, Lee HC, et al. Effects of race/ethnicity and $\mathrm{BMI}$ on the association between height and risk for spontaneous preterm birth. Am J Obstet Gynecol 2015;213:e701-9.

12. Leeuw V V, Ch L, E Y. Données périnatales en Région bruxelloise Année 2014. Brussels: Centre d'Épidémiologie Périnatale, 2015.

13. Minsart AF, Buekens $P$, De Spiegelaere M, et al. Missing information in birth certificates in Brussels after reinforcement of data collection, and variation according to immigration status. A population-based study. Arch Public Health 2012;70:25.

14. van der Ploeg T, Austin PC, Steyerberg EW. Modern modelling techniques are data hungry: a simulation study for predicting dichotomous endpoints. BMC Med Res Methodol 2014;14:137.
15. Voigt M, Heineck G, Hesse V. The relationship between maternal characteristics, birth weight and pre-term delivery: evidence from Germany at the end of the 20th century. Econ Hum Biol 2004;2:265-80.

16. Lao TT, Pun TC. Preterm birth unrelated to maternal height in Asian women with singleton gestations. J Soc Gynecol Investig 2001;8:291-4.

17. Honest H, Hyde CJ, Khan KS. Prediction of spontaneous preterm birth: no good test for predicting a spontaneous preterm birth. Curr Opin Obstet Gynecol 2012;24:422-33.

18. Auger N, Giraud J, Daniel M. The joint influence of area income, income inequality, and immigrant density on adverse birth outcomes: a population-based study. BMC Public Health 2009;9:237.

19. Reagan PB, Salsberry PJ. Race and ethnic differences in determinants of preterm birth in the USA: broadening the social context. Soc Sci Med 2005;60:2217-28.

20. Reeske A, Kutschmann M, Razum O, et al. Stillbirth differences according to regions of origin: an analysis of the German perinatal database, 2004-2007. BMC Pregnancy Childbirth 2011;11:63.

21. Zanconato $\mathrm{G}$, lacovella $\mathrm{C}$, Parazzini $\mathrm{F}$, et al. Pregnancy outcome of migrant women delivering in a public institution in northern Italy. Gynecol Obstet Invest 2011;72:157-62.

22. Cacciani L, Asole S, Polo A, et al. Perinatal outcomes among immigrant mothers over two periods in a region of central Italy. BMC Public Health 2011;11:294.

23. Minsart AF, De Spiegelaere M, Englert Y, et al. Classification of cesarean sections among immigrants in Belgium. Acta Obstet Gynecol Scand 2013;92:204-9.

24. Urquia ML, Glazier RH, Blondel B, et al. International migration and adverse birth outcomes: role of ethnicity, region of origin and destination. J Epidemiol Community Health 2010;64:243-51.

25. Gillet E, Saerens B, Martens G, et al. Fetal and infant health outcomes among immigrant mothers in Flanders, Belgium. Int $J$ Gynaecol Obstet 2014;124:128-33.

26. Goedhart $\mathrm{G}$, van Eijsden M, van der Wal MF, et al. Ethnic differences in preterm birth and its subtypes: the effect of a cumulative risk profile. BJOG 2008;115:710-9.

27. El-Sayed AM, Galea S. Explaining the low risk of preterm birth among arab americans in the United States: an analysis of 617451 births. Pediatrics 2009;123:e438-e445.

28. Moloy HC. Evaluation of the pelvis in obstetrics. Philadelphia: Saunders, 1951.

29. Christian P. Maternal height and risk of child mortality and undernutrition. JAMA 2010;303:1539-40.

30. Kramer MS, McLean FH, Eason EL, et al. Maternal nutrition and spontaneous preterm birth. Am J Epidemiol 1992;136:574-83.

31. Patel RR, Steer P, Doyle P, et al. Does gestation vary by ethnic group? A London-based study of over 122,000 pregnancies with spontaneous onset of labour. Int J Epidemiol 2004;33:107-13.

32. Schaible UE, Kaufmann SH. Malnutrition and infection: complex mechanisms and global impacts. PLoS Med 2007;4:e115.

33. Timasheva Y, Putku M, Kivi R, et al. Developmental programming of growth: genetic variant in $\mathrm{GH} 2$ gene encoding placental growth hormone contributes to adult height determination. Placenta 2013;34:995-1001. 